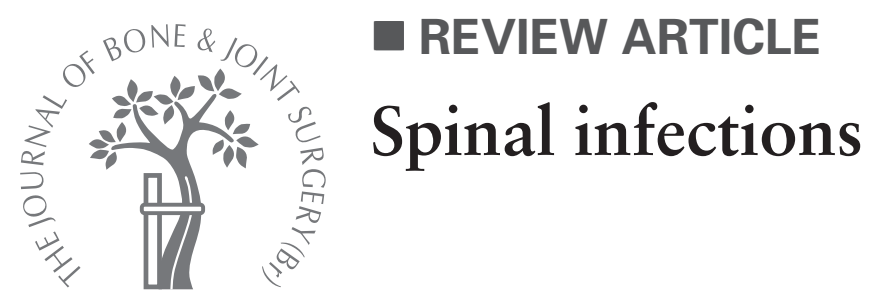

\section{S. Govender}

From the University of Natal, Durban, South Africa

S. Govender, MD, FRCS, Professor and Head of Department

Department of Orthopaedic Surgery

University of Natal, Private

Bag 7, Congella 4013,

Durban, South Africa.

Correspondence should be sent to Professor S.

Govender; e-mail:

Katia@ukzn.ac.za

(C)2005 British Editorial Society of Bone and Joint Surgery

doi:10.1302/0301-620X.87B11. $16294 \$ 2.00$

$J$ Bone Joint Surg [Br]

2005;87-B:1454-8.
The axial skeleton accounts for $2 \%$ to $7 \%$ of all cases of osteomyelitis. ${ }^{1-3}$ Predisposing factors include diabetes mellitus, malnutrition, substance abuse, HIV infection, malignancy, the long-term use of steroids, renal failure and septicaemia. ${ }^{4-8}$ Protein malnutrition results in a decreased number of circulating T-cells with impaired production of cytokines. ${ }^{9}$ Steroidmediated immunosuppression disarms both the humeral and cellular response to infectious agents. HIV/AIDS predisposes patients to fungal infection and tuberculosis (TB) because of defects in the neutrophils, a decreased cell count and leucocyte dysfunction. ${ }^{10} \mathrm{HIV}$ and TB form a lethal combination and one-third of the increase in the incidence of TB has been attributed to associated HIV infection. Globally, there are more than two million people with spinal TB and its incidence is expected to increase. ${ }^{11}$ Local conditions which predispose individuals to an epidural abscess include direct extension from an infected contiguous source and iatrogenic inoculation. The latter may occur during invasive diagnostic and therapeutic techniques and accounts for $14 \%$ to $26 \%$ of spinal epidural abscesses. The delay in diagnosis and treatment is commonly due to the insidious presentation of the physical signs and symptoms especially in children and the elderly, and may increase the morbidity and mortality. ${ }^{12,13}$ Pyogenic spondylitis is more common in the elderly patient. ${ }^{14,15}$ Vertebral osteomyelitis, discitis and epidural abscesses represent a continuum of indolent infection in the immunocompromised host. The management of spinal infections requires a multidisciplinary approach involving spinal surgeons, specialists in infectious diseases, radiologists, rehabilitation personnel, psychologists and the social services.

\section{Modes of infection}

Haematogenous infection is usually from either the skin, respiratory tract, genitourinary tract, gastrointestinal tract or the oral cavity, giving rise to bacteraemia. ${ }^{6,15}$ The two major routes for haematogenous dissemination are by way of the venous and arterial circulations. Batson ${ }^{16}$ demonstrated retrograde flow from the pelvic venous plexus to the perivertebral plexus. In the cervical spine the extensive prevertebral retropharyngeal venous plexus may act as a conduit for the spread of bacteria. Wiley and Trueta ${ }^{17}$ suggested that bacteria can become lodged in the arteriolar network at the vertebral endplate. There is a difference in the pathophysiology of spinal infection in children and adults. In children, inoculation is through the persisting vascular channels in the disc space and discitis may occur after bacteraemia. In adults, the disc is avascular and the organisms invade the end-arterial arcades in the metaphyseal region adjacent to the disc. The infection then spreads by direct extension with rupture of the infective focus through the endplate into the disc. It may extend from the vertebral body to the subligamentous paravertebral area, the epidural space and contiguous vertebral bodies. ${ }^{18}$ Spinal instability after destruction of the disc, bone and posterior elements may cause compression of the spinal cord or nerve root.

Causative organisms. The common organisms include Staphylococcus aureus and streptococcus species and in intravenous drug abusers gram-negative bacilli are frequently isolated. Mycobacterium tuberculosis, fungal infections and parasitic infestations are uncommon but are usually seen in immunocompromised patients. ${ }^{10}$ Organisms of low virulence such as coagulase-negative staphylococci and Streptococcus viridans may cause indolent infections. Salmonella osteomyelitis may be responsible for infection in patients who are immunocompromised and in children with sickle-cell anaemia. ${ }^{9}$ In approximately one-third of patients the infective organisms cannot be identified. $^{12}$

\section{Clinical features}

Neurological deficit is associated with a spinal epidural abscess in about one-third of 
patients. ${ }^{19}$ An ischaemic mechanism has been proposed resulting from occlusion of the blood flow to the spinal cord, thrombosis of the venous drainage system or an abscess-induced vasculitis. However, it is likely that the primary aetiology of neural damage is mechanical compression with vascular compromise playing a secondary role. ${ }^{20}$ In more than $90 \%$ of patients, unremitting back pain which is not relieved by rest is the most common presenting complaint. Pain may be accompanied by constitutional symptoms including loss of weight and a poor appetite. Cachexia with generalised lymphadenopathy is suggestive of HIV infection. Between $60 \%$ and $70 \%$ of patients have a fever which is also associated with discitis after open surgery. ${ }^{8,13,21,22}$ Backache following iatrogenic discitis may develop after open or percutaneous procedures which violate the intervertebral disc. The reported incidence of iatrogenic discitis varies between $1 \%$ and $11 \%$ and is higher in patients who are treated without prophylactic antibiotics. ${ }^{22,23}$ Physical examination may reveal localised spinal tenderness with paraspinal muscle spasm and marked limitation of spinal movement. In advanced disease, especially in TB, patients with infection of the lumbar spine may present with a painful gibbus or a psoas abscess. The diagnosis of spondylitis and discitis in children is frequently delayed. In a child vertebral infection should be suspected when a limp is present. There is refusal to bear weight and the spine assumes a flexed position. Children may present with abdominal pain especially those with involvement of the dorsolumbar spine. ${ }^{24,25}$ Cervical spondylitis can spread anteriorly and cause a retropharangeal abscess resulting in dysphagia and dyspnoea or a mediastinitis when it extends inferiorly. The rate of progression of neurological compromise is variable. It may take days to develop or become manifest within hours after the onset of symptoms. ${ }^{26}$ Patients who have undergone catheterisation of the epidural space need regular monitoring since an epidural abscess may appear up to 60 days later. ${ }^{27-29}$

\section{Haematological aspects}

An increased white cell count has been noted in two-thirds of patients with spondylitis. The ESR and the level of Creactive protein are frequently raised. Blood cultures provide early isolation of the organism in approximately twothirds of patients. ${ }^{4,14,15}$ The search for potential causes of bacteraemia is essential and includes screening for pathological conditions. In intravenous drug abusers a cardiac ultrasound scan is needed to rule out endocarditis. Comorbidities should be investigated and treated and the nutritional profile assessed.

\section{Imaging}

Plain radiography may reveal evidence of vertebral osteomyelitis, a paraspinal abscess, osteoporosis or spinal deformity. However, the sensitivity and specificity of plain radiography are very low especially in the early stages. The earliest sign which is loss of definition and irregularity of the vertebral endplate appears between two and eight weeks after the initial symptoms. ${ }^{30}$ In pyogenic infection, involvement of the pedicle, lamina and the spinous process is uncommon and should raise suspicion of $\mathrm{TB} .{ }^{31}$ Three major sites of involvement of the vertebral body in TB include the peridiscal, central and anterior areas. The most common form is the peridiscal type which occurs adjacent to the vertebral endplate with the infection spreading around a motion segment. Extension to the adjacent vertebra occurs as the abscess tracks beneath the anterior longitudinal ligament. Central involvement affecting the vertebral body may be mistaken for a tumour. Anterior disease causes scalloping of the vertebral body. ${ }^{32}$ In the absence of abnormal radiological findings in the early stages of spondylitis, a three-phase technetium bone scan is sensitive ( $87 \%$ to $98 \%$ ) and specific (91\% to $100 \%$ ) for infection. ${ }^{2}$ A gallium-67 citrate scan may be useful during follow-up in order to monitor treatment since it is less sensitive to bone remodelling and gives a more accurate assessment of the degree of activity of the infective process. ${ }^{2}$ Recent advances in imaging have substantially changed the assessment of spinal infection. MRI is sensitive, specific and accurate (96\%, 94\% and $92 \%$, respectively). It is the investigation of choice for planning treatment and follow-up of suspected cases of spondylitis. ${ }^{1}$ Gadolinium-enhanced MRI is currently most suited for the examination of the spine in patients with suspected vertebral osteomyelitis and epidural abscess. The latter may be accurately localised and defined from the pattern of uptake of the contrast material. Although gadolinium-enhanced MRI scans are highly sensitive and specific they often overestimate the presence and extent of the epidural abscess within the spinal canal. ${ }^{33,34}$ When such scans are contraindicated or not available, CT with myelography provides an alternative means of defining the location and extent of the infection. ${ }^{13}$

\section{The place of antibiotics}

Before the introduction of modern antibiotic therapy, the mortality after vertebral osteomyelitis was approximately $25 \%$. ${ }^{33}$ This treatment, together with surgical debridement and stabilisation, decreased it to less than $15 \% .{ }^{34}$ Early diagnosis has improved the outcome by allowing appropriate prompt treatment and preventing the formation of abscesses, instability and neurological deficit. The nutritional status and the comorbidities must be treated before surgery. Hyperalimentation is an effective way to maximise nutrition before surgery. Infection creates a catabolic state and the goal of nutritional supplementation is to restore the patient to their pre-morbid nutritional status. ${ }^{11}$ In socioeconomically deprived communities the patients are often malnourished and their nutrition is further impaired by the infection.

The place of antibiotics in the management of discitis in children is uncertain. Good results have been achieved in several studies. ${ }^{25,26,35,36}$ However, Scoles and Quinn ${ }^{24}$ found that all their patients were asymptomatic at the time 
of discharge from hospital whether or not antibiotics had been administered. By contrast, Ring and Wenger ${ }^{35}$ observed that patients treated with intravenous antibiotics for at least six days had a more rapid resolution of their symptoms and the lowest likelihood of developing recurrent symptoms. Although the value of antibiotic treatment is uncertain, immobilisation with casting or bracing is essential.

Intravenous antibiotics should provide broad-spectrum cover for the most common causative organisms before surgical decompression. The treatment is then tailored to the specific pathogen following culture and obtaining antibiotic sensitivities. Consultation with microbiologists and specialists in infectious diseases is essential to optimise antibiotic cover and to aid in identifying possible sources of bacteraemia. It has been suggested that intravenous antibiotics should be continued for a minimum of four to six weeks for pyogenic osteomyelitis and an epidural abscess. ${ }^{4,5,14}$ The duration of the administration of oral antibiotics is dependent upon clinical and laboratory evidence that the infection is resolving. ${ }^{11}$ Antituberculosis treatment is recommended for 12 months and compliance is essential to prevent multidrug resistance, especially in the immunocompromised patient. ${ }^{37}$ Amphotericin B and 5flucytosine have been used in fungal infections as a combination therapy because of their synergistic effect. The duration of antifungal treatment is dependent on the sideeffects, clinical response and radiological outcome. ${ }^{38-41}$

Surgical drainage remains the primary treatment of an epidural abscess, but more recently antimicrobial therapy without surgery has been advocated. ${ }^{38,42}$ However, there are no prospective studies which evaluate both forms of treatment.

\section{Conservative management}

Non-surgical treatment may be appropriate in a patient who is at risk for operation because of concurrent medical conditions and in patients who have been completely paralysed for more than 48 to 72 hours. Medical management may also be advocated for an anterior epidural abscess following vertebral osteomyelitis in patients with no neurological deficit. It has been suggested that the conservative approach is optimal for lesions confined to the lumbosacral spine in patients who are neurologically intact. ${ }^{13}$ Those on medical treatment should be carefully monitored on a regular basis because they may develop rapid and irreversible neurological deterioration. Apart from clinical assessment, haematological parameters such as the ESR and follow-up MR gadolinium scans are essential to monitor the response to medical treatment. In post-injection discitis there is a tendency towards spontaneous resolution over a period of several months. However, disabling back pain which may continue in some patients is usually resistant to conservative management. These patients may benefit from a clearance of the anterior disc space and interbody fusion using an autogenous graft from the iliac crest. The use of pro- phylactic antibiotics is important to prevent iatrogenic discitis in addition to the use of strict aseptic techniques during all procedures which violate the intervertebral disc. ${ }^{22,23}$ Since most epidural abscesses are situated posteriorly and are not associated with vertebral osteomyelitis, a laminectomy is effective. Instrumentation and fusion should be considered if the posterior elements are compromised by infection, deformity or by the decompressive procedure itself. Because of the poor host immune response corticosteroids should not be administered, but may be considered when a patient with progressive neurological deficit is being prepared for surgical decompression. ${ }^{13}$

\section{Percutaneous techniques}

The accuracy of closed vertebral needle biopsy in patients with spondylitis without neurological deficit varies and has been reported to be about $70 \%$. A negative result may be due to insufficient tissue or to the administration of antibiotics before biopsy. ${ }^{43,44}$ A core sample obtained from a Craig needle biopsy is preferable to fine-needle aspiration except when an abscess cavity is present. An open biopsy is indicated when closed-needle biopsy fails to identify an organism, when the infection is inaccessible to closed techniques and in the presence of a neurological deficit or a painful progressive deformity. Biopsy specimens should be sent for Gram staining and aerobic, anaerobic, TB and fungal cultures. ${ }^{18}$ In an anterior epidural abscess which is frequently associated with vertebral osteomyelitis, anterior decompression followed by bone grafting and instrumentation when necessary is essential. ${ }^{45-48}$ Transpedicular discectomy has been advocated in the early stages of spondylodiscitis in order to control infection, expedite healing and to prevent the progression of bone destruction, which may lead to a painful kyphotic deformity and instability. Patients treated by this method reported decreased pain within 24 hours with subsequent resolution of the neurological deficit. ${ }^{49}$ More recent advances in the management of an epidural abscess include percutaneous drainage of the spinal canal. ${ }^{21,50}$ This method may be applicable to patients who are immunocompromised and are not candidates for an open decompression. Although it may limit the peri-operative morbidity, percutaneous measures provide limited access to the pathological anatomy. Recent refinements include an endoscopic technique allowing direct visualisation and debridement of the abscess. ${ }^{51}$

\section{Outcome}

Reihsaus et $\mathrm{al}^{6}$ have presented an extensive review of the literature on a spinal epidural abscess. They noted that in the last decade approximately $20 \%$ of patients who were diagnosed late with an epidural abscess succumbed to it. Recent studies report a mortality rate of approximately $10 \%{ }^{21,22}$ Although the mortality has declined as a result of improved techniques of management and early recognition, permanent neurological sequelae remain common. Host immunocompetence has an important influence on outcome. A 
suboptimal response to treatment has been noted in patients taking steroids and in those with HIV infection. Poor results have been correlated with multiple medical comordities and infection with methicillin-resistant staphylococci after previous spinal surgery. ${ }^{4,5,52,53}$ The neurological outcome depends on the location of the abscess. It has been reported that patients with spondylitis and epidural abscess in the cervical and thoracic spine have a poor outcome when compared with those who have involvement of the lumbar spine. ${ }^{20,48}$ In addition, the neurological outcome has been shown to be inversely related to the severity of the neural deficit at presentation.

Sampath and Rigamonti ${ }^{5}$ showed that patients presenting with significant neurological compromise were more likely to have an unsatisfactory outcome. In their study of 29 patients with a severe neurological deficit, six died and ten did not regain the ability to walk. Lu et $\mathrm{al}^{21}$ concluded that the only significant $(\mathrm{p}<0.001)$ prognostic factor was the presence of a motor deficit before treatment. Any substantial delay in diagnosis or management has a detrimental effect on the overall clinical outcome. Several studies have shown no improvement in the neurological outcome or recovery in patients who were paraplegic for more than 12 hours before surgery. ${ }^{12,13}$

\section{Conclusion}

In the elderly and immunocompromised patients, the diagnosis of spondylitis is often delayed because of a blunted immune response and lack of signs and symptoms. A high index of suspicion of spinal infection is warranted in children and patients who present with unremitting spinal or radicular pain. Blood cultures, appropriate imaging and biopsy are essential in making an early diagnosis. Adequate pre-operative nutritional support and management of the predisposing factors are essential to ensure a successful outcome.

\section{References}

1. Dagirmanjian A, Schils J, McHenry M. MR Imaging of spinal infections. Magn Reson Imaging Clin N Am 1999;7:525-38.

2. Tyrrell PNM, Cassar-Pollucino VN, McCall IW. Spinal infection. Eur Radio/1999; 9:1066-77.

3. Stabler A, Reiser MF. Imaging of spinal infection. Radiol Clin North Am 2001;39: 115-35.

4. Del Curling $\mathbf{O} \mathbf{J r}$, Gower DJ, McWhorter JM. Changing concepts in spinal epidural abscess: a report of 29 cases. Neurosurg 1990;27:185-92.

5. Sampath P, Rigamonti D. Spinal epidural abscess: a review of epidemiology, diagnosis and treatment. J Sp Disord 1999;12:89-93.

6. Reihsaus E, Waldbaur H, Seeling W. Spinal epidural abscess: a meta-analysis of 915 patients. Neurosurg Rev 2000;23:175-204.

7. Boszcyk BM, Krause P, Bolay H, Hohmann F, Mayer HM. Spinal epidural abscess following blunt pelvic trauma. Eur Spine J 2000;9:80-4

8. Soehle M, Wallengang T. Spinal epidural abscesses: clinical manifestations, prognostic factors and outcomes. Neurosurg 2002;51:79-85.

9. Broner FA, Garland DE, Zigler JE. Spinal infections in the immunocompromised host. Orthop Clin North Am 1996;27:37-46.

10. Delafuente JC. Nutrients and immune response. Rheum Dis Clin North Am 1991;17: 203-12.

11. Moon MS. Tuberculosis of the spine: controversies and a new challenge. Spine 1997; 22:1791-7.
12. Maslen DR, Jones SR, Crislip MA, et al. Spinal epidural abscess: optimizing patient care. Arch Intern Med 1993;153:1713-21.

13. Khanna RK, Malik GM, Rock JP, Rosenblum ML. Spinal epidural abscess: evaluation of factors influencing outcome. Neurosurg 1966;39:958-64.

14. Danner RI, Hartman BJ. Update of spinal epidural abscess: 35 cases and review of the literature. Rev Infect Dis 1987;9:265-74.

15. Hlavin ML, Kaminski HJ, Ross JS, Ganz E. Spinal epidural abscess: a ten-year perspective. Neurosurg 1999;27:177-84.

16. Batson OV. The vertebral system of veins as a means for cancer dissemination. Prog Clin Can 1976;3:1-18.

17. Wiley AM, Trueta J. The vascular anatomy of the spine and its relationship to pyogenic vertebral osteomyelitis. J Bone Joint Surg [Br] 1959;41-B:796-809.

18. Tay BKB, Deckey J, Hu SS. Spinal infections. J Am Acad Orthop Surg 2002;10: 188-97.

19. Still JM, Abranson R, Law EJ. Development of an epidural abscess following staphylococcal septicaemia in an acutely burned patient: case report. J Trauma 1995;38: 158-9.

20. Lasker BR, Harter DH. Cervical epidural abscess. Neurology 1987;37:1747-53.

21. Lu CH, Change WN, Lui CC, Lee PY, Chang HW. Adult spinal epidural abscess: clinical features and prognostic factors. Clin Neurol Neurosurg 2002;104:306-10.

22. Tang HJ, Lin $\mathbf{J H}$, Lui YC, Li CM. Spinal epidural abscess: experience with 46 patients and evaluation of prognostic factors. J Infect 2002;45:76-81

23. Rohde V, Meyer B, Schaller C, Hassler WE. Spondylodiscitis after lumbar discectomy: incidence and a proposal for prophylaxis. Spine 1998;23:615-20.

24. Scoles PV, Quinn TP. Intervertebral discitis in children and adolescents. Clin Orthop 1991;266:70-90

25. Wenger DR, Bodechko WP, Gilday DL. The spectrum of intervertebral disc space infection in children. J Bone Joint Surg [Am] 1978;60-A:100-8.

26. Phillips GE, Jefferson A. Acute spinal epidural abscess: observation from 14 cases. Postgrad Med J 1979;55:712-15

27. Nordberg G, Mark H. Epidural abscess after epidural analgesia treated successfully with antibiotics. Acta Anaesthesiol Scand 1998;42:727-31.

28. Kindler CH, Seeberger MD, Staender SE. Epidural abscess complicating epidural anaesthesia and analgesia: an analysis of the literature. Acta Anaesthesiol Scand 1998;42:614-20

29. Royakker AANM, Willigers H, van Der Ven AJ, et al. Catheter-related epidural abscesses: don't wait for neurological deficit. Acta Anaesthesiol Scand 2002;46: 611-15

30. Babinchak TJ, Riley DK, Rotheram EB Jr. Pyogenic vertebral osteomyelitis of posterior elements. Clin Infect Dis 1997;25:221-4.

31. Rajasekaran S. The problem of deformity in spinal tuberculosis. Clin Orthop 2002 398:85-92.

32. Gun JP. Pyogenic osteomyelitis of the spine: differential diagnosis through clinical and radiographic observations. J Bone Joint Surg [Am] 1946;28:29-39.

33. Carragee EJ. Pyogenic vertebral osteomyelitis. J Bone Joint Surg [Am] 1997;79-A: 874-80.

34. Sharif HS. Role of MRI in the management of spinal infections. AJR Am J Roentgenol 1992;158:1333-45

35. Ring D, Wenger DR. Pyogenic infectious spondylitis in children: the evolution to current thought. Am J Orthop 1996;25:342-8.

36. Tali ET. Spinal infections. Eur J Rad 2004;50:120-33

37. Govender S, Parbhoo AH, Kumar KPS, Annamalia K. Anterior spinal decompression in HIV positive patients with tuberculosis. J Bone Joint Surg [Br] 2001;83-B: 864-7.

38. Govender S, Kumar KP. Aspergillus spondylitis in immunocompetent patients. Int Orthop 2001;25:74-6.

39. Lang EW, Pitts LH. Intervertebral disc space infection caused by Aspergillus fumigatus. Spine 1996;5:207-9.

40. Herron LD, Kissel P, Smilovitz D. Treatment of coccidiodal spinal infection: experience in 16 cases. J Spinal Disord 1997;10:215-22.

41. Govender S, Mutasa E, Parbhoo AH. Cryptococcal osteomyelitis of the spine. J Bone Joint Surg [Br] 1999;81-B:459-61.

42. Mampalam TJ, Rosegay H, Andrews BT, Rosenblum ML, Pitts LH. Nonoperative treatment of spinal epidural infections. J Neurosurg 1989;71:208-10.

43. Kornblum MB, Wesolowski DP, Fischgrund JS, Herkowitz HN. Computed temography-guided biopsy of the spine: a review of 103 patients. Spine 1998;23:81-5.

44. Sulaiman 00, Govender S. Outcome of fluoroscopic core needle biopsy of lumbar spine. S A Ortho J 2004;3:30-5.

45. Govender $\mathbf{S}$. The outcome of allografts and anterior instrumentation in spinal tuberculosis. Clin Orthop 2002;398:60-6. 
46. Emery SE, Chan DP, Woodward HR. Treatment of heamatogenous pyogenic vertebral osteomyelitis with anterior debriment and primary bone grafting. Spine 1989;14: 284-91.

47. Yimaz C, Selek HY, Gurkan I, Erdemli B, Korkusuz Z. Anterior instrumentation for the treatment of spine tunerculosis. J Bone Joint Surg [Am]1999;81-A:1261-7.

48. Eismont F, Bohlman HH, Soni PL, Goldberg VM, Freehafer AA. Pyogenic and fungal vertebral osteomyelitis with paralysis. J Bone Joint Surg [Am] 1983;65-A: 19-29.

49. Hadjipavlou A, Crow W, Borowski A, et al. Percutaneous transpedicular discectomy and drainage in pyogenic spondylodiscitis. Am J Orthop 1998:27:188-97.
50. Hori K, Kano T, Fukushige T, Sano T. Successful treatment of epidural abscess with a percutaneous introduced 4-French catheter foe drainage. Anesth Analg 1997; 84:1384-6.

51. Roselli R, Lacoangeli M, Pompucci A, et al. Anterior cervical epidural abscess treated by endoscopy-assisted minimally invasive microsurgery via posterior approach. Minim Invasive Neurosurg 1998;41:161-5.

52. Koppel BS, Tuchman AJ, Mangiardi JR, Daras M, Weitzner I. Epidural spinal infection in intravenous drug abusers. Arch Neurol 1988;45:1331-7.

53. Harrington P, Millner PA, Veale D. Inappropriate medical management of spinal epidural abscess. Ann Rheum Dis 2001;60:218-22. 